\title{
DIY orthodontics - safe, cheaper option or dangerous gamble?
}

As new companies are expanding into the UK promising 'DIY orthodontics' that remove the need to see a professional before starting treatment, questions are being asked about just how safe this cheaper approach really is. Adrian O'Dowd investigates.

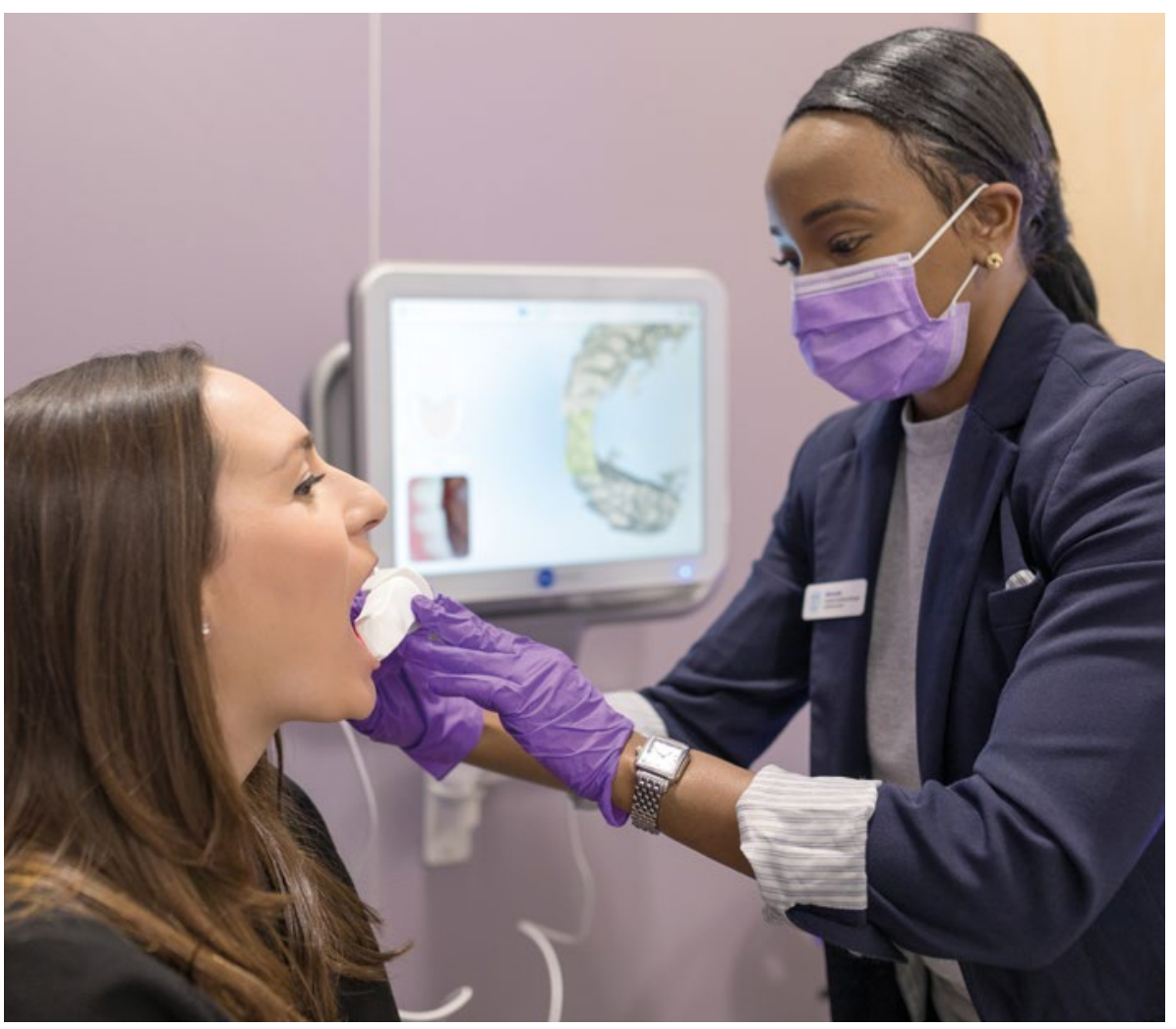

$\mathrm{T}$ he pursuit of the so-called 'perfect smile' appears to be increasingly popular in the UK as private dentistry in particular is attracting customers with products promising dazzling teeth whitening and orthodontic transformations.

At the same time, healthcare is embracing technology with promised solutions to problems through growing use of telemedicine, teledentistry, smart wear technology, and digital solutions.

Combined, these two trends are helping develop a market for tackling misaligned teeth in ways that are causing concern in some parts of the dental profession.
One of the newest firms involved in this development is US teledentistry company SmileDirectClub which opened in the United Kingdom in July 2019, promising customers cheaper aligner therapy to correct their misaligned teeth than previously offered by competitors.

\section{New approach}

The approach works by inviting customers to visit one of the company's 21 SmileShop locations in the UK where 3D photographs are taken of their smile. Globally, the company operates around 366 SmileShops across the US, Canada, Ireland, Australia, New Zealand, and Hong Kong, as well as the UK.
Another option is for customers to request an impression kit, prescribed by a UK registered dentist or orthodontist. A healthcare professional will create a custom treatment plan and prescribe custom-made, clear aligners, which are then shipped directly to the customer.

SmileDirectClub is emphasising the cost of its service, offering either the option of a single payment of $£ 1,499$, or 12 payments of $£ 120$ per month with a deposit of $£ 199$, which includes two additional sets of retainers valued at $£ 70$ per set.

These prices make its service one of the cheapest and best value for money of its kind, says the company, thanks to 'innovations across the supply chain', meaning that its direct-to-consumer clear aligner therapy costs around $60 \%$ less than traditional braces, with an average treatment length of six months.

The company was founded in 2014 and says it has helped more than 750,000 people and has more than 5,400 employees.

A spokesperson for SmileDirectClub says: 'We're very pleased with our brand's early reception in the UK. We currently have 1,980 reviews collected across 21 SmileShops with an average of 4.9-star rating, which we take as a strong sign of customer satisfaction.'

The model offers a great advantage, argues the company, saying: 'We're providing a convenient and more affordable way for more people to have access to care.'

In addition to offering direct-to-consumer remote clear aligner therapy in the US, Canada, Australia, New Zealand, Ireland, Hong Kong, and the UK, the company also recently announced plans to offer clear aligners through the wholesale channel, providing dentists and orthodontists an in-office option. 


\section{« International concerns}

Concerns with the company's approach have been raised from various quarters.

The American Association of Orthodontists (AAO), which represents around 18,000 dental professionals, has lodged complaints with authorities in 36 US states, alleging that SmileDirectClub's service was 'illegal and creates medical risks'.

In July of last year, the AAO said ${ }^{1}$ it had 'serious concerns about direct-to-consumer orthodontics' when it saw more than 935 customer complaints at that time on the Better Business Bureau's website for SmileDirectClub, LLC ('SmileDirectClub' or 'SDC'), as well as other reviews and stories where individuals were claiming issues with certain direct-to-consumer companies. ${ }^{2}$

In a statement the AAO said: 'Last year, the AAO filed complaints with 36 state dental boards and attorneys general, alleging specific statutory and regulatory violations by SmileDirectClub.

'Those statutes and regulations are in place to protect public health and safety. Many of the complaints filed by the AAO are being reviewed in their respective jurisdictions, and the AAO will continue to provide relevant information to dental boards in the interest of public health and safety.'

In addition, the California Assembly Bill $1519^{3}$ that was passed in October of last year will introduce changes in the regulation of the company's teledentistry business model in that state and will give the Dental Board of California regulation control until January 2024.

SmileDirectClub has responded, sayings: 'Simply put, this bill represents the dental lobby's thinly-veiled attempt to protect traditional dentistry at the expense of Californians.

'While this bill does not preclude SmileDirectClub's continued operations in California, we disagree with the unnecessary hurdles and costs to Californians that need care but struggle to afford it that this bill could create.

'The undebated, clinically unsupported, and ill-advised policy changes that are included in this bill ... have created arbitrary barriers to technological innovation.'

In an article ${ }^{4}$ by Forbes magazine in September of last year, it said the company's approach had 'garnered fierce opposition' from the dental industry and mentions the fact that the American Dental Association issued a resolution 'strongly discouraging' people from using the service and submitted complaints to both the Federal Trade Commission and Food \& Drug Administration.

In addition, Hindenburg Research, a short-seller organisation that specialises in forensic financial research, investigated SmileDirectClub last year, and spoke to multiple former employees, competitors, and customers to prepare a report. ${ }^{5}$

It concluded: 'We believe the company is carelessly cutting corners in a field of specialised medicine, putting customer safety at risk.'

The most commonly cited differentiator relative to SmileDirectClub, said
'There are now several companies that are operating on this scanning, remote delivery of clear aligners approach. It's an area in which people are looking to expand and it is potentially quite lucrative.

'I have engaged with SmileDirectClub on their Facebook page. It's not at all clear what their analysis is of the oral health of the patients that they are treating.

'They mention that they request information from dentists but a lot of these people that are turning up perhaps aren't going to regular oral screens in normal dental practices so some of them could have significant undiagnosed problems that would end up causing serious problems during their treatment.

\section{'The American Association of Orthodontists has lodged complaints with authorities in 36 US states, alleging that SmileDirectClub's service was "illegal and creates medical risks"'}

Hindenburg, was that the competitors included substantial involvement from an orthodontist throughout the process, often including multiple visits and direct guidance.

SmileDirectClub has strongly rejected these claims, saying: 'SmileDirectClub puts consumers' access to a safe, affordable, and quality teeth straightening experience first.

'There is no scientific or medical justification to substantiate the false claims made about the safety, effectiveness or standard of doctor care using our teledentistry model and the licensed doctors in our affiliated network. We will vigorously defend ourselves and our business model in order to continue to pursue our company's mission.'

\section{UK market}

Back in the United Kingdom, the company's arrival has not been greeted with universal praise.

The British Dental Association (BDA) is worried the company's approach is potentially dangerous and has raised concerns with health regulator the Care Quality Commission (CQC) and dental regulator the General Dental Council (GDC), which is now actively investigating all companies offering DIY orthodontics.

Eddie Crouch, Vice-Chair of the BDA's Principal Executive Committee, says:
'Often these patients will need a clinician's intervention, for example, interproximal reduction. Many of my colleagues are raising concerns because if you then partake in a treatment plan that you have not devolved, how vulnerable are you to litigation and complaint if things don't go right?

'I'm thinking of things like the periodontal state. If it is not assessed, then these appliances can hasten tooth loss and various other things because they will be moving teeth that are potentially unstable.'

\section{Regulatory concerns}

Another issue for the BDA is the company's dental care professionals (DCP) working at the SmileShops and what they are being asked to do with scanning.

'In my opinion, I believe these DCPs may be perhaps acting outside their scope of practice,' says Mr Crouch. 'The GDC [General Dental Council] advice about scanning is that it should be done under the direction of a dentist and it's a grey area when people just walk in off the street.

'Whilst SmileDirectClub say there are dentists - although they do not name any particular dentists - if they were open and transparent, you would be able to see which clinicians are actually overseeing the scanning.' " 
4 The company argues that its approach is safe and appropriate.

Its spokesperson says: 'Through our teledentistry platform, SmileDirectClub provides our affiliated network of licensed dentists and orthodontists with ample information on their patient to safely straighten his or her smile, including the customer's oral photos, medical and dental history, the customer's chief complaint, 3D scan images and the draft treatment plan for modification and approval as specified by the treating doctor.

'Similar to treatment in a traditional brick-and-mortar setting, the treating doctor may request $\mathrm{X}$-rays, assess the patient for periodontal disease, or ask for additional clinical information before considering whether their patient is a viable candidate for clear aligner therapy.

'SmileDirectClub's platform provides for ongoing 90-day check-ins during which customers communicate with their treating doctor about their progress and satisfaction with their treatment, and any clinical concerns that need to be addressed depending on the circumstances of each case.'

\section{Official scrutiny}

The regulators are monitoring these types of service and the GDC revealed in February 2020 that is has approached providers of 'direct to consumer orthodontics' to seek clarification on the procedures they follow and how GDC registrants may be involved.

The GDC says it has received reports that providers of 'direct-to-consumer orthodontics' are offering services that may not include face to face patient contact with a registrant authorised to provide direct services to patients.

In a statement, the regulator says: 'Our view is that for all dental interventions, this important interaction between clinician and patient should take place at the beginning of the patient consultation.'

This face to face meeting allows the clinician to carry out a proper assessment before making a clinical judgement to approve a suitable course of treatment and to address any underlying oral health problems while also giving the patient a chance to ask questions and provide valid, informed consent.

A GDC spokesperson told the $B D J$ : 'We are aware of a number of organisations offering services remotely, which could constitute dentistry as defined in law, including the growth in 'direct-to-consumer orthodontics'. "

\section{National campaign on DIY orthodontics}

Other organisations share some of the BDA's concerns and the Oral Health Foundation and British Orthodontic Society (BOS) are launching a campaign this spring to warn of the potential risks of 'DIY' [do it yourself] orthodontics.

The Safe Brace campaign website - http:// www.safebrace.org/ - sets out the issues with relevant and useful advice for patients who are interested in orthodontic treatment.

Professor Jonathan Sandler, President of the BOS, says: 'This kind of service [DIY orthodontics] seems to be a growing trend and it's caught the imagination of the public. My first concern is the safety of the treatment that is being recommended and whether the subject's teeth and the supporting tissues of the teeth are healthy enough to withstand this kind of treatment.

'Secondly, we are concerned whether the teeth are being moved to a healthy and/or appropriate position. Without an in-depth assessment of the start position and having a view of where we are trying to move the teeth to, then it's impossible to make this judgement.'

BOS is launching the Safe Brace campaign with the Oral Health Foundation to try and reach a wide audience, he explains, saying: 'We want to get high quality information out to our potential patients so that they can reach an informed decision.'

Dr Nigel Carter, Chief Executive of the Oral Health Foundation, adds: 'SmileDirectClub is the largest company doing this and has been operating in the states for some time, but there appear to be others coming into the field. It's the whole principle of DIY orthodontics which is the issue.

'My concerns are that it's the fact that you've got no real diagnosis process although some of the companies will claim they have orthodontists looking at everything.

'The whitening cases established that a dentist needs to be involved. It's not protectionist to say that. It's protecting the public. I think it's going to be fraught with disaster.

'It seems as if you are providing half a service with DIY orthodontics and the risks for the patient are huge. The best advice for patients is to visit a trained clinician. Saving money is not the best reason to go and accept what is potentially inferior treatment that could leave you with further problems.'

\section{First-hand opinion}

Maintaining the human touch when treating clients is essential, according to Asif Chatoo, an Orthodontic Specialist with a special interest in lingual braces and aligners as well as owner of The London Lingual Orthodontic Clinic in London.

'The idea of aligners has revolutionised orthodontics and allowed it to be carried out in a more accessible and comfortable way to a high standard,' he explains.

'However, the advent of direct marketing of aligners is unsafe for the patient in that as far as I can see, the patients are fitting them, but there has been no diagnosis by a clinician.
'I find the whole trend towards consumers taking products and services from the internet alarming. It worries me because there is the potential for the consumer to be damaged by irresponsible tooth movement. There is also the potential for other serious conditions which might be picked up by a clinician to be overlooked.

'As our regulatory body, the GDC should surely have a responsibility in ensuring all forms of dentistry in the UK and all forms of dental practice - of which this is one - should be monitored carefully by a clinician who is registered with them.'

DIY orthodontics seems to have captured the public's imagination, but the issues around its safety are far from settled and could take some time to be smoothed out.

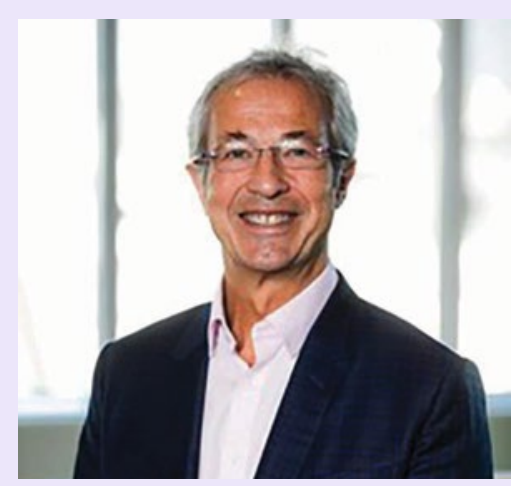

Professor Jonathan Sandler, BOS President

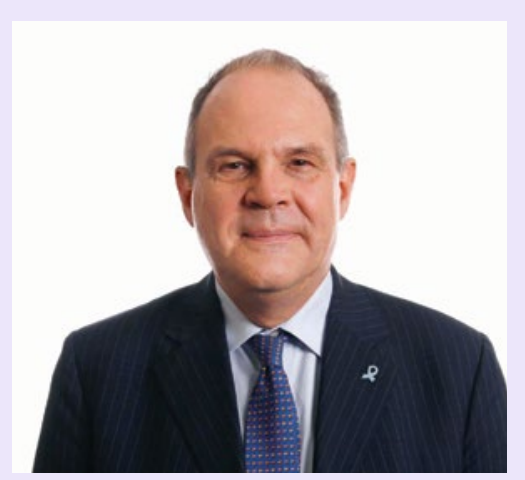

Dr Nigel Carter, Chief Executive of the Oral Health Foundation

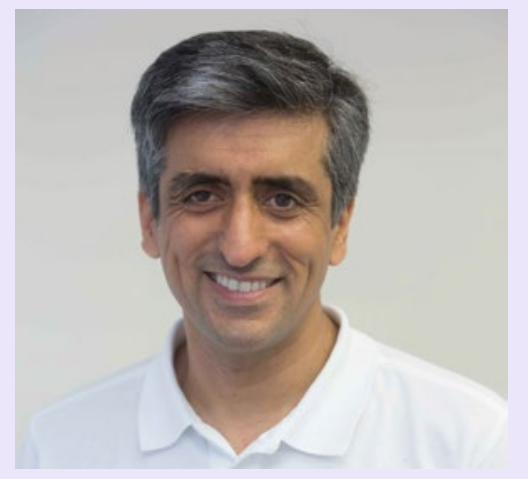

Dr Asif Chatoo, an Orthodontic Specialist 
14 'We are looking into a number of regulatory issues in relation to this and we look forward to sharing our position once that work has progressed.

'While this work is ongoing, should we receive information that could amount to an allegation of professional impairment or of illegal practice, each case will continue to elements of care remotely which may have previously been carried out in a more traditional setting. We also know that this has raised some concerns among professionals and this is something we take seriously.

'Along with our colleagues in the GDC, we will continue to work with the profession and people who use services to understand

\title{
'The GDC says it has received reports that providers of "direct-to-consumer orthodontics" are offering services that may not include face to face patient contact with [an authorised] registrant'
}

be reviewed individually and progressed as appropriate. We will issue a further statement when we have evaluated the evidence we are gathering.'

The main NHS regulator, the Care Quality Commission, is also aware that issues have been raised.

Janet Williamson, its Deputy Chief Inspector and Lead for Dentistry, says: 'With new technology comes new ways of offering services but it remains the case that people have the right to receive high quality, safe care, regardless of how it is delivered.

'We know that some providers are already looking to do things differently and offering how these developments might fit in into the regulatory landscape and what we can all do together to make sure people get the care they deserve.'

\section{Scan reliability and accuracy}

The BDA's Eddie Crouch also worries about the reliability of the scans being taken by a DCP, as he explains: 'The scanning of someone's mouth is the practice of dentistry - everyone would accept that. We have made representation on this at the highest level.'

$\mathrm{Mr}$ Crouch also has concerns about the premises being used, as he says: 'These premises are not inspected by the Care
Quality Commission. We have written to the GDC and the CQC questioning their role in regulating these operations.

'The regulators also need to look at whether the premises that they are operating from are safe and secure for patients. Cross-infection control procedures are important, for example.

'In circumstances before, where we have seen people have teeth whitening clinics in shopping centres where the practice of dentistry is ongoing, the CQC have acted in situations like that. You see very few of those now on the high street.'

\section{References}

1. American Association of Orthodontists. American Association of Orthodontists Discusses Patient Health And Safety Information Regarding DirectTo-Consumer Orthodontics. 2 July 2019. Available at: https://www.prnewswire.com/news-releases/ american-association-of-orthodontists-discusses-patient-health-and-safety-information-regarding-direct-to-consumer-orthodontics-300878975.htm (accessed 25 February 2020).

2. Better Business Bureau. SmileDirectClub Customer Complaints. Available at: https://www.bbb.org/us/ tn/nashville/profile/cosmetic-dentistry/smiledirectclub-0573-37111672 (accessed 25 February 2020)

3. California Legislative Information. Assembly Bill No. 1519. October 2019. Available at: https://leginfo. legislature.ca.gov/faces/billNavClient.xhtml?bill_ id=201920200AB1519 (accessed 25 February 2020).

4. Debter L. SmileDirectClub Gets Chilly Reception In Latest Billionaire-Minting IPO. Forbes1 11 September 2019. Available at: https://www.forbes.com/sites/laurendebter/2019/09/11/smiledirectclub-ipo/\#6cac54f86aca (accessed 25 February 2020)

5. Hindenburg Research. SmileDirectClub: Moving Fast and Breaking Things in People's Mouths - 85\% Downside. 4 October 2019. Available at: https://hindenburgresearch. com/smiledirectclub-moving-fast-and-breaking-thingsin-peoples-mouths/ (accessed 25 February 2020).

\section{CONFERENCE REPORT}

\section{The Scottish Oral Health Research Collaboration Conference 2019}

\author{
By Sarah Clyde, DCT2 Research and Restorative Dentistry Glasgow Dental Hospital
}

The Scottish Oral Health Research Collaboration (SOHRC) Conference was held in Dundee on 1 October 2019. This took place at the Dental Health Education Centre.

There were three main themes of this year's conference: Public Health and Health Services, Craniofacial and Dental Education. These three themes were demonstrated throughout the morning by the Collaboration's research groups who gathered for the event.

Attendees were welcomed by Chief Dental Officer Tom Ferris who opened the day. Professor Angus Walls, Director of the Dental Institute in Edinburgh and
Dean of Clinical Sciences, then guided the morning session which consisted of threeminute $\mathrm{PhD}$ presentations demonstrating the depth of research across the three SOHRC themes. These presentations were followed by opening the floor to questions from the attendees. This was a very interactive session which allowed the $\mathrm{PhD}$ students to engage with their audience and showcase their hard work.

The afternoon session was opened by Professor Jeremy Bagg, Professor of Clinical Microbiology in Glasgow University. He then introduced the keynote lecturer, Professor Jan Clarkson, DHSRU Co-Director, Professor of Clinical Effectiveness, University of Dundee. She gave a thought provoking presentation which focused on the TRiaDs group, a multidisciplinary research collaboration within the Scottish Clinical Effectiveness Programme, or SDCEP. The main focus of this lecture was the idea of translating knowledge into practice.

I was an attendee at this conference and found it to be very inspiring and exciting to be in an area with such expertise in various fields of dentistry. I would recommend attendance at the next conference as I am sure it will be just as impressive! 